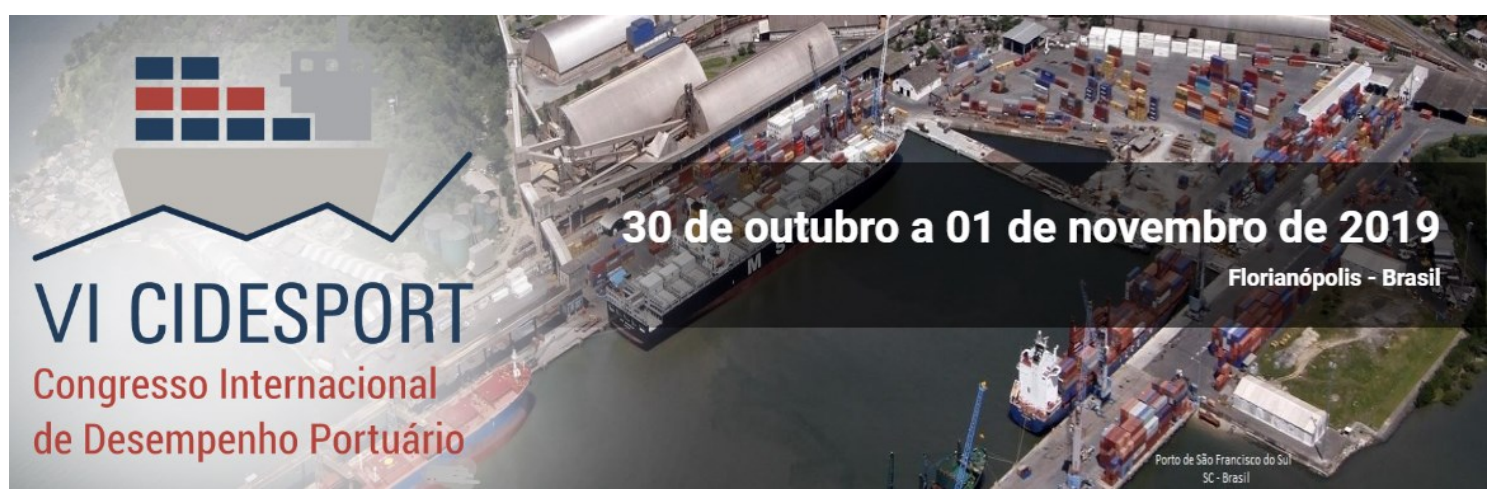

\title{
PROPOSIÇÃO DE MÉTODO PARA FORMULAÇÃO DE PLANO OPERACIONAL NO CONTEXTO DOS PLANOS DE DESENVOLVIMENTO E ZONEAMENTO (PDZ) DOS PORTOS BRASILEIROS
}

\author{
Alexandre Sá dos Santos \\ Empresa Maranhense de Autoridade Portuária - EMAP
}

Aline Huber

Universidade Federal de Santa Catarina - UFSC

Carlos Frederico Alves

Universidade Federal de Santa Catarina - UFSC

Nubia Ilka Carbonari

Universidade Federal de Santa Catarina - UFSC

Tiago Buss

Universidade Federal de Santa Catarina - UFSC

Resumo: $O$ presente artigo apresenta uma proposição de método para elaboração do plano operacional no contexto dos Planos de Desenvolvimento e Zoneamento Portuário (PDZ). O objetivo é contribuir para formulação desses planos operacionais, que se caracterizam como um conjunto de ações que conduzem ao atingimento dos objetivos no âmbito estratégico do setor portuário nacional. Propõe-se que a elaboração das ações do Plano Operacional seja desenvolvida usando como base a ferramenta $5 \mathrm{~W} 2 \mathrm{H}$. Cada ação deve ser formulada levando em consideração as diretrizes estratégicas de instrumentos de políticas socioambientais, da política nacional de transportes, do planejamento do setor portuário, do território do município em que o porto encontra-se inserido e dos instrumentos de planejamento da própria Autoridade Portuária. O método proposto foi aplicado na elaboração do PDZ do Porto do Itaqui e resultou em 77 ações operacionais $100 \%$ alinhadas com o Plano Mestre do Porto do Itaqui e com forte aderência aos demais instrumentos de políticas e diretrizes do setor.

Palavras-chave: Planejamento portuário. Plano de desenvolvimento e zoneamento portuário. Plano operacional.

\section{INTRODUÇÃO}

Esta pesquisa trata-se de um estudo de caso que tem como objetivo a proposição de um método para a formulação do plano operacional no contexto

${ }^{*}$ A revisão gramatical, ortográfica, ABNT ou APA foi realizada pelos autores. 
dos PDZs dos portos brasileiros. Sendo assim, tem-se como objetivos específicos: i) revisar o marco legal que traça as diretrizes para o planejamento estratégico do setor portuário brasileiro e para a elaboração dos PDZs dos portos organizados; ii) analisar as principais metodologias adotadas para a elaboração de planos de ações no âmbito de planejamento portuário; iii) propor um método para a formulação do plano operacional dos portos brasileiros; e iv) analisar a experiência da aplicação do método na elaboração do PDZ do Porto do Itaqui.

De acordo com Miguel (2012), o estudo de caso possui caráter empírico e investiga um fenômeno dentro de um contexto real contemporâneo por meio da análise aprofundada de um ou mais objetos, possibilitando o amplo e detalhado conhecimento sobre o fenômeno e a geração de teorias. As características do estudo de caso tornam-no extremamente útil para a avaliação de teorias e métodos propostos, uma vez que, em muitos casos, não se busca apenas apresentar os resultados, como também investigar as relações entre processos e resultados (YIN, 1993).

O presente estudo é realizado em três etapas, indicadas na Figura 1, com vistas ao atendimento dos objetivos apresentados.

Figura 1 - Etapas da execução da pesquisa

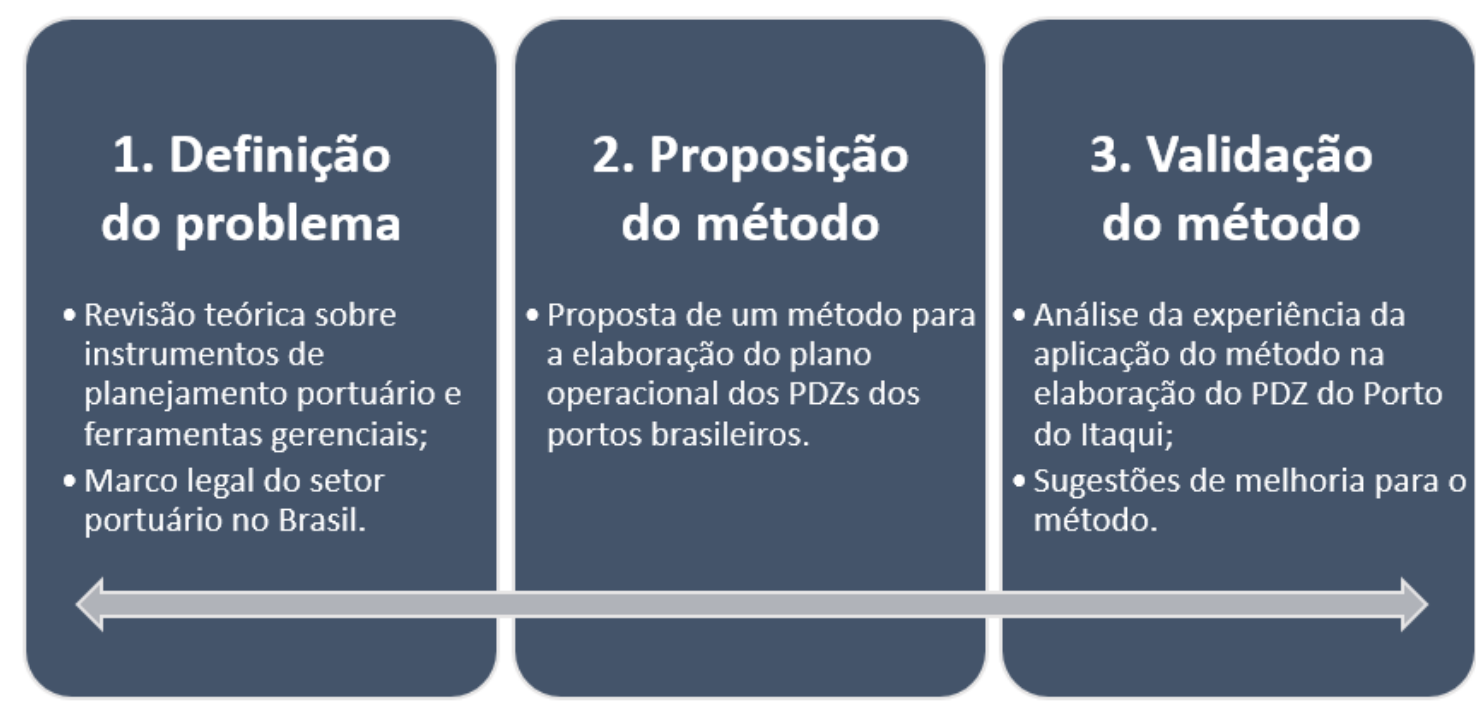

Fonte: Elaborada pelos autores.

A sequência deste artigo, portanto, é estruturada em quatro capítulos: 0 Capítulo 2 contempla o referencial teórico e apresenta os resultados da revisão da literatura, com enfoque nos níveis e ferramentas do planejamento organizacional e na estrutura do planejamento portuário nacional. No Capítulo 3 apresenta-se o método proposto para a elaboração do plano operacional no contexto dos PDZs dos portos brasileiros e no Capítulo 4 é realizada a validação do método, por meio da exposição da experiência da sua aplicação na elaboração do PDZ do Porto do Itaqui. No Capítulo 5 apresentam-se as considerações finais.

\section{REFERENCIAL TEÓRICO}

Para a revisão da literatura acerca das metodologias adotadas para a formulação de planos de ações no setor portuário, foram utilizadas duas 
técnicas: a revisão narrativa e a revisão sistemática. A revisão narrativa tem caráter arbitrário e não busca a generalização ou compilação de publicações acerca de um tema específico (PARÉ; KITSIOU, 2017; PETTICREW; ROBERTS, 2006), tendo como objetivo permitir a análise de publicações consagradas sobre a temática da pesquisa, além da obtenção de informações específicas acerca do contexto analisado, como é o caso dos instrumentos de planejamento de organizações referência no contexto portuário e os instrumentos normativos que definem as diretrizes para o planejamento portuário nacional.

Já a revisão sistemática consiste em um processo estruturado e transparente que, por meio de uma busca em múltiplas fontes, procura responder aprofundadamente uma questão específica e sintetizar o estado da arte acerca de um determinado tema (DAVIES; CROMBIE, 2001; PARÉ; KITSIOU, 2017; PETTICREW; ROBERTS, 2006). Para tanto, foram consultadas duas bases de periódicos que contém publicações nas áreas de engenharias e ciências socioeconômicas, entre outras: a ScienceDirect, por conta da relevância em âmbito global das publicações nela contidas, e a Scielo, que contempla uma base extensa e qualificada de publicações nacionais.

Foram utilizados os seguintes conjuntos de palavras-chave e operadores booleanos para as buscas nas bases de dados ScienceDirect e Scopus, em inglês: ("operational plan" OR "operations plan" OR "action plan") AND port AND NOT airport; e para a busca na base de dados Scielo, em português: ("plano operacional" OR "plano de ação" OR "plano de ações") AND (porto OR portuário) AND NOT aeroporto. Delimitou-se que os termos devem constar no título, resumo ou entre as palavras-chave das publicações, e não foram realizadas delimitações quanto à data das publicações.

\subsection{Níveis e ferramentas de planejamento organizacional}

A estratégia de uma organização é definida pelo conjunto de objetivos e de políticas principais responsáveis por orientar o seu comportamento a longo prazo, e pela delimitação de um propósito central e expresso em termos dos serviços a serem prestados por ela à sociedade (CHIAVENATO, 2002). Drucker (1984) define o planejamento estratégico como o processo contínuo de tomada de decisões que envolvem riscos, que prevê uma organização sistemática das atividades necessárias à execução dessas decisões, e permite, por meio da retroalimentação, a mensuração de seus resultados em confronto com as expectativas alimentadas.

Chiavenato (2002) explica que o planejamento estratégico se preocupa, basicamente, com o que fazer, e não em como fazer. Sendo assim, a definição de planos de ações específicos e detalhados fica a cargo do planejamento operacional, havendo uma instância intermediária entre o nível estratégico e o operacional, o nível tático, responsável pela elaboração do planejamento operacional e pela manutenção das atividades da organização conforme padrões programados, cabendo ao nível operacional da organização a execução das ações definidas. A Figura 2 ilustra os três níveis de planejamento citados. 
Figura 2 - Níveis de planejamento nas organizações

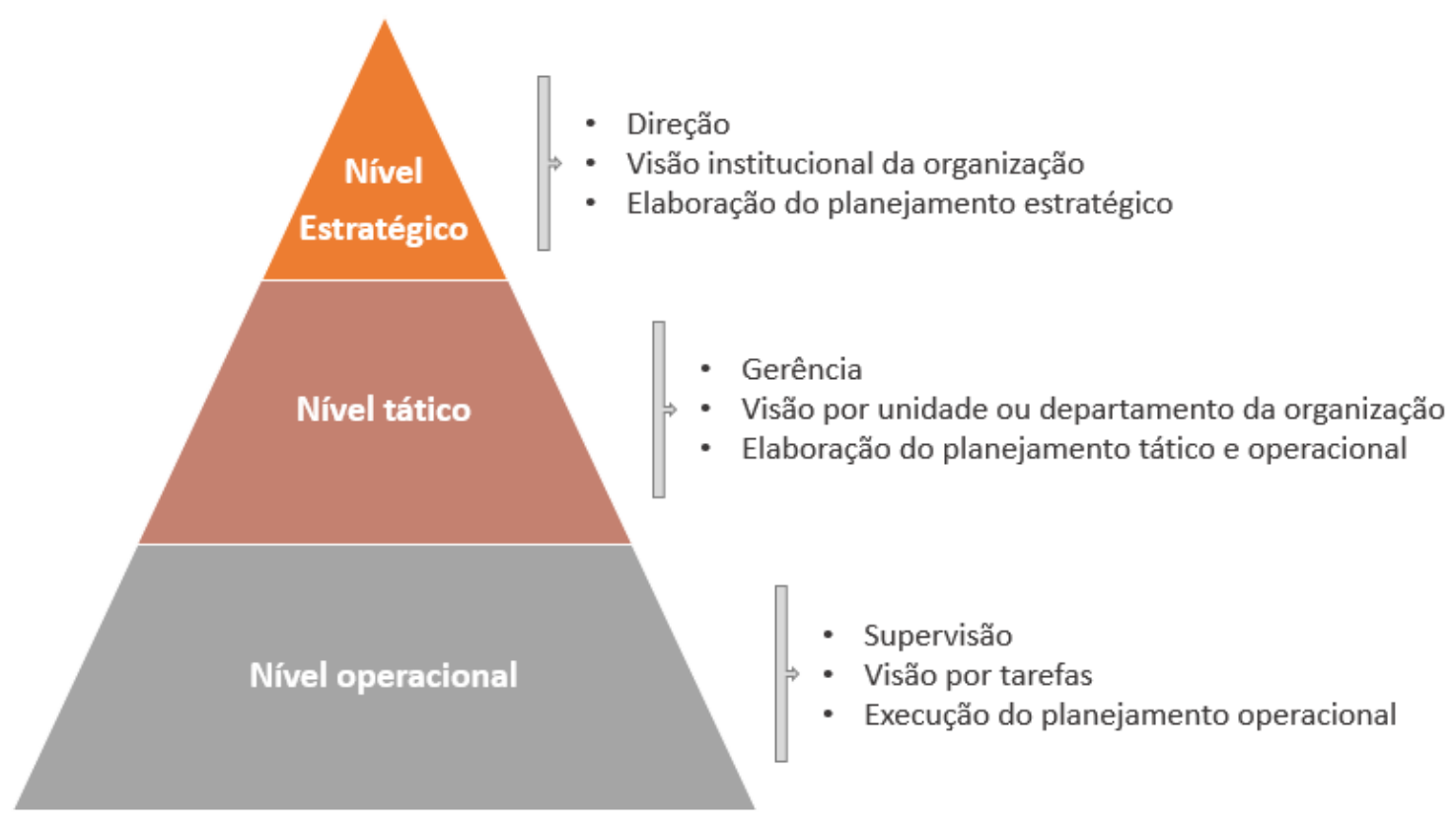

Fonte: Elaborada pelos autores.

Com relação ao planejamento do setor portuário, especificamente, a administração do porto encarrega-se por uma variedade de atividades direcionadas à utilização dos recursos disponíveis para atender às necessidades dos usuários, cabendo ao planejamento estratégico a definição de estratégias com vistas à obtenção de vantagem competitiva para alcançar seus objetivos de mercado e financeiros (UNCTAD, 1993).

Em se tratando das formas de elaboração do planejamento estratégico, as mesmas podem variar conforme as características da organização e o setor na qual estão envolvidas. Na Figura 3, são identificados alguns procedimentos usualmente contemplados na elaboração do planejamento estratégico, e técnicas que podem ser complementares para a aplicação de cada etapa. 
Figura 3 - Etapas e técnicas utilizadas para a elaboração do planejamento estratégico

\section{Etapas}

\section{Técnicas}

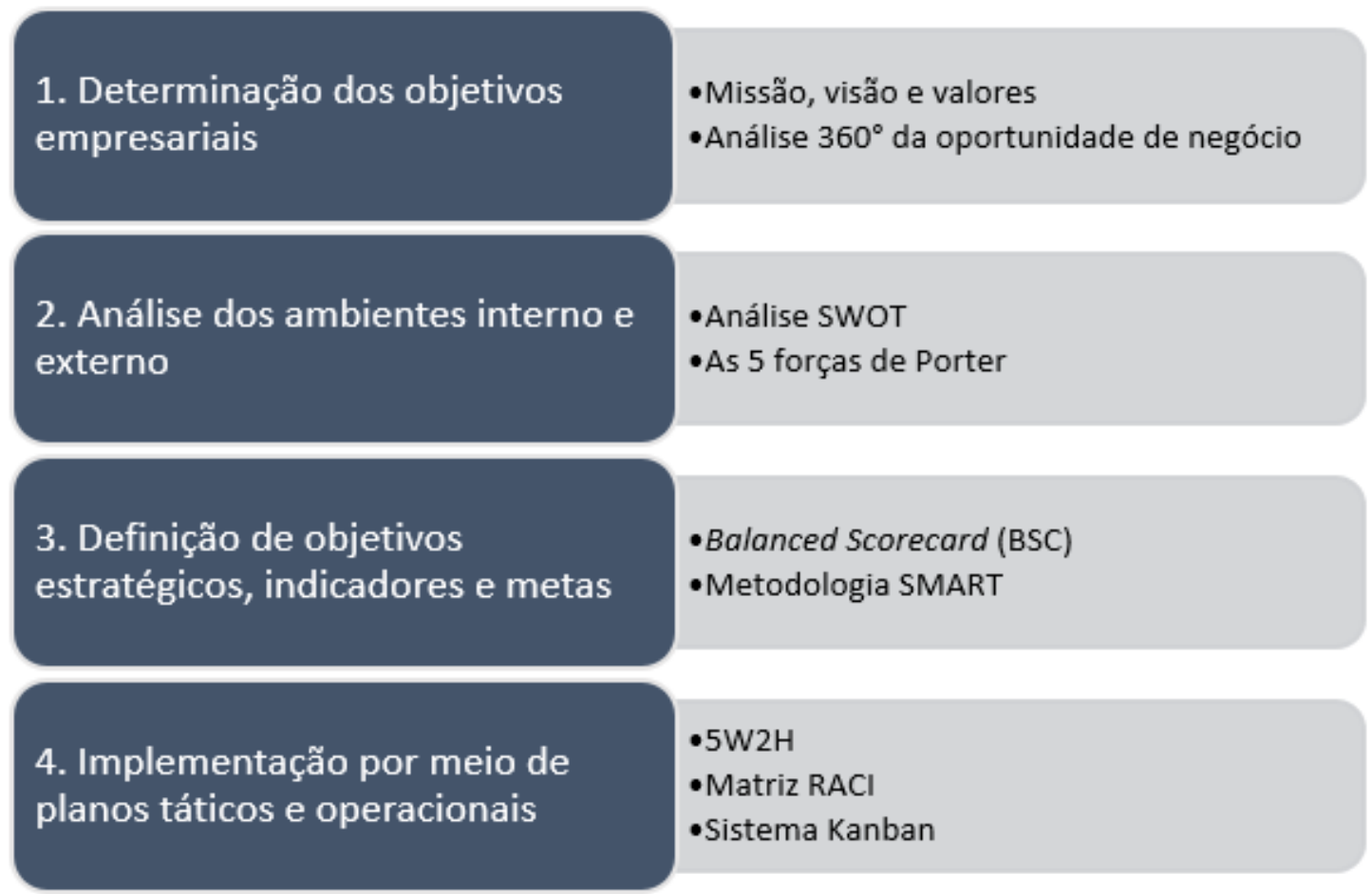

Fonte: Elaborada pelos autores.

Dentre as técnicas listadas, destaca-se o Balanced Scorecard (BSC), que é amplamente aplicado em diversos setores, e tem caráter versátil, pois além de ser um instrumento útil para a definição de objetivos estratégicos, indicadores e metas, conforme indicado na Figura 3, transita entre os níveis estratégico e tático da organização, e pressupõe análises relacionadas às seguintes perspectivas: financeira, clientes, processos internos e aprendizado e crescimento. Sendo assim, a sua aplicação implica em importantes insights para a elaboração das demais etapas do planejamento estratégico.

De acordo com Kaplan e Norton (1997, p. 2), idealizadores do método, o BSC "traduz a missão e a estratégia das empresas num conjunto abrangente de medidas de desempenho que serve de base para um sistema de medição e gestão estratégica". A Agência Nacional de Transportes Aquaviários (ANTAQ) e a Empresa Maranhense de Administração Portuária (EMAP) são exemplos de organizações do setor portuário que aplicam esta técnica como aspecto central do seu planejamento estratégico, que, por sua vez, são elaborados de forma alinhada aos instrumentos de planejamento estratégico elaborados pelo Governo Federal, dentres eles o Plano Nacional de Logística Portuária (PNLP) e os Planos Mestre Portuários. Conforme indicado pela Autoridade Portuária do Porto do Itaqui, o BSC permite o acompanhamento dos objetivos, indicadores e metas internos, otimizando os processos e permitindo que se observe os efeitos das ações implementadas anualmente (EMAP, 2019).

Para que o planejamento estratégico possa ser executado nos demais níveis da empresa, ele deve ser desdobrado em um plano de ações para cada divisão ou departamento da empresa, no nível tático, a ser aplicado no nível 
operacional (CHIAVENATO, 2002). O plano operacional, portanto, trata-se do conjunto de ações alinhado aos objetivos específicos da organização, que são monitorados por indicadores e metas, e conduzem ao atingimento dos objetivos no âmbito estratégico.

Já a elaboração de planos operacionais pode ser realizada por meio da aplicação de diversas técnicas, destacando-se entre elas o $5 \mathrm{~W} 2 \mathrm{H}$, que, de acordo com Marshall Junior (2003), é uma ferramenta de cunho gerencial, de fácil entendimento, utilizada na elaboração de planos de ação a partir da definição de responsabilidades, métodos, prazos, objetivos e recursos. Cada ação planejada, de acordo com o método $5 \mathrm{~W} 2 \mathrm{H}$, deve conter as informações: "por quê?"; "o quê?"; "onde?"; "quando?"; "quem?"; "como?"; e "quanto custa?", sendo que as iniciais de cada um destes questionamentos, em inglês, formam o nome da técnica.

Um aspecto que deve ser levado em consideração no processo de planejamento e implementação do plano operacional é a gestão da qualidade, fator que, de acordo com Paladini (2009), leva à maximização da eficiência do processo produtivo. Sendo assim, a utilização de técnicas como o PDCA, acrônimo para, planejar, executar, verificar e atuar, em inglês, configura-se como um elemento essencial para o atingimento dos objetivos do plano em qualquer instância da organização, sendo recomendável que seja prevista no planejamento estratégico.

\subsection{Instrumentos de planejamento do setor portuário}

De acordo com PIANC (2014), os instrumentos de planejamento utilizados com maior frequência no setor portuário são: Plano de Investimentos, Plano Gerencial, Plano de Negócios, Plano de Zonamento, Planejamento Estratégico e Plano Mestre, cada um com escopo específico, imputando-se ao Plano de Zoneamento a responsabilidade pela definição de planos de ações relacionados a princípios definidos no âmbito do Plano Mestre. Na prática, entretanto, é comum que essas informações sejam concatenadas em um único documento elaborado pela administração do porto.

Neste estudo, foram analisados os documentos disponibilizados ao público pelas autoridades portuárias de regiões com alto desenvolvimento do setor portuário, como o Porto de Roterdã, na Holanda; Porto de Los Angeles, Porto de Nova lorque e Nova Jersey e Porto de Seattle, nos Estados Unidos da América; Porto de Vancouver, no Canadá; Porto de Port Hedland, Porto de Melbourne e Porto de Brisbane, na Austrália. O Quadro 1 apresenta a referência de cada um desses documentos, o nome do instrumento de planejamento analisado, e indica se o mesmo contempla ou não um plano de ações. 
VI CIDESPORT/2019

Congresso Internacional

de Desempenho Portuário

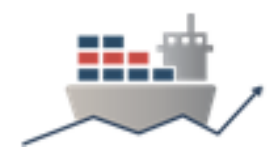

Quadro 1 - Planejamento estratégico de portos selecionados em âmbito global

\begin{tabular}{|lll|}
\hline \multicolumn{1}{|c|}{ REFERÊNCIA } & INSTRUMENTO DE PLANEJAMENTO & PLANO DE AÇÕES \\
\hline Port Hedland Port Authority (2012) & Port Development Plan 2012-2016 & Não \\
\hline Port Metro Vancouver (2014) & Land Use Plan & Sim \\
\hline Port of Brisbane (2015) & Land Use Plan 2015 & Não \\
\hline Port of Melbourne Corporation (2006) & Port Development Plan 2006-2035 & Não \\
\hline Port of Rotterdam Authority (2011) & Port Vision 2030 & Sim \\
\hline Port of Seattle (2018) & Long Range Plan 2018-2022 & Não \\
\hline The Port Authority of New York and New Jersey (2019) & Port Master Plan 2050 & Não \\
\hline The Port of Los Angeles (2018) & Port Master Plan & Não \\
\hline
\end{tabular}

Fonte: Elaborado pelos autores.

Conforme apresentado no Quadro 1, a maior parte dos documentos que formalizam as diretrizes estratégicas das autoridades portuárias analisadas não incluem informações relacionadas ao planejamento operacional, ou, analogamente, à formulação de planos de ações. De modo geral, esses documentos contemplam apenas os objetivos organizacionais, a análise interna e externa e a definição de objetivos estratégicos.

As exceções são os instrumentos de planejamento do Porto de Vancouver e do Porto de Roterdã, que definem planos no nível operacional, com a identificação de ações e prazos, sendo que no segundo caso há um alto nível de detalhamento e designa-se o departamento ou a entidade responsável pela execução de cada uma das ações. Ressalta-se que não foram encontradas informações relacionadas ao planejamento de alguns portos de destaque no oriente médio, leste e sudeste asiático, como: Porto de Dubai (Jebel Ali), nos Emirados Árabes Unidos; Porto de Xangai e Porto de Shenzhen, na China; e Porto de Singapura, em Singapura.

\subsubsection{Definição do problema}

Os primeiros estudos voltados à eficiência das operações portuárias no Brasil foram desenvolvidos na década de 60, pelo Departamento Nacional de Portos e Vias Navegáveis - DNPVN (BOGOSSIAN, 2011). Em 1974 foram elaborados os Planos Diretores Portuários (PDP), desenvolvidos para 29 portos, situados em 17 estados e cujo conteúdo era composto pela caracterização da situação atual do porto, identificação dos elementos condicionantes do Plano Diretor, dimensionamento da expansão portuária no período de 1975-1985 e um plano decenal. Estas duas últimas seções eram destinadas à recomendação de ações para expansão dos portos, para atendimento da demanda projetada e continham um orçamento com os valores estimados para implantação das melhorias e cronograma de execução (BRASIL, 1974).

Em 1979 os primeiros PDPs foram atualizados pela Empresa de Portos do Brasil (Portobrás) - substituta do DNPVN, mantendo o horizonte de 1984. A segunda atualização desses planos ocorreu em 1986, com horizonte de planejamento até 1997 e promoveu a alteração da nomenclatura do documento para Planos de Desenvolvimento Portuários. Conforme destaca Silva (2013) 
estes vieram a ser a última atualização de um documento de planejamento nacional portuário em quase 25 anos.

O cenário foi alterado com a Lei $n^{\circ} 8.630$ de 1993, que, ao delegar ao Conselho de Autoridade Portuária (CAP) a competência em aprovar o Plano de Desenvolvimento e Zoneamento dos portos a serem desenvolvidos pelas Administrações Portuárias, descentralizou o planejamento do setor. Em 2009, a Portaria SEP/PR $n^{\circ} 414$ estabeleceu o escopo, as diretrizes, os objetivos gerais e os procedimentos mínimos para a elaboração dos PDZs (SILVA, 2013). A referida portaria indicava que as conclusões do PDZ deveriam indicar as metas a serem alcançadas, os instrumentos e as ações necessárias para sua execução, bem como os benefícios a serem auferidos aos usuários em decorrência dos investimentos esperados (BRASIL, 2009). Essa portaria foi revogada com a publicação da Portaria SEP/PR n ${ }^{\circ}$ 3, de 2014.

Atualmente o planejamento do setor portuário nacional é previsto pela Lei $12.815 / 2013$, pelo Decreto $n^{\circ} 8.033 / 2013$ e pela Portaria $n^{\circ} 3$, de 7 de janeiro de 2014, que determinam quatro instrumentos de planejamento para o setor portuário: o Plano Nacional de Logística Portuária (PNLP), o Plano Mestre, o Plano Geral de Outorgas e o PDZ. As estratégias setoriais são definidas por meio da elaboração do PNLP, e complementadas pelos Planos Mestres dos complexos portuários (BRASIL, 2013a, 2013b, 2014).

Destaca-se que o PNLP é planejamento estratégico do setor, que identifica a vocação dos portos. Ao Plano Mestre cabe uma visão sobre cada unidade portuária, considerando o previsto no PNLP, e que tem como resultado o estabelecimento de um Plano de Melhorias e Investimentos para o porto. O Plano Geral de Outorgas (PGO), por sua vez, pode ser entendido com um plano de ação voltado à execução de outorgas de novos terminais. O PDZ tem caráter operacional e é desenvolvido pela Administração Portuária, com o objetivo de compatibilizar as políticas de desenvolvimento do território onde o Porto se localiza com as informações do PNLP e Plano Mestre. Assim, ao passo que a Lei determina que é o Poder Concedente o responsável pelo planejamento setorial (PNLP, Plano Mestre e PGO) e que cabe à Autoridade Portuária a elaboração do PDZ (BRASIL, 2013a, 2013b, 2014).

Assim, a elaboração de planos operacionais no setor portuário está prevista a nível do PDZ, que é regulamentado em sua forma e conteúdo pela Portaria SEP/PR $n^{\circ} 3 / 2014$, a qual define o PDZ como o "instrumento de planejamento operacional da Administração Portuária, e que compatibiliza as políticas de desenvolvimento urbano dos municípios, do estado e da região onde se localiza o porto, visando, no horizonte temporal, o estabelecimento de ações e de metas para a expansão racional e a otimização do uso de áreas e instalações do porto, com aderência ao Plano Nacional de Logística Portuária PNLP e respectivo Plano Mestre" (BRASIL, 2014).

Além destes documentos, há outros dois instrumentos desenvolvidos pelas autoridades portuárias brasileiras, que são o Planejamento Estratégico das Autoridades Portuárias e os Planos de Negócios, que muitas vezes incluem planos de ações táticas e operacionais em seus resultados. No caso do Plano Mestre e do Plano Estratégico da Autoridade Portuária, muitas vezes as diretrizes apresentadas nos documentos também abarcam caráter de planejamento tático, não somente estratégico.

O Plano Operacional tem o objetivo de amparar a Autoridade Portuária no fortalecimento dos instrumentos de gestão e controle, buscando o alinhamento 
das iniciativas e o emprego eficiente dos recursos públicos, e desta forma gerar valor na infraestrutura de transporte e logística portuária.

O marco regulatório do setor portuário brasileiro, prevê a obrigatoriedade da elaboração de planos operacionais no âmbito do PDZ dos portos organizados brasileiros. Na Portaria SEP/03 indica o escopo mínimo das ações operacionais, porém não determina métodos e procedimentos sistêmicos para o desenvolvimento e padronização desses planos de ações.

Nessa temática, buscou-se com a busca sistemática do referencial teórico, obter procedimentos e métodos de formação de planos de ações operacionais aplicados a portos. Foram encontrados um total de 111 publicações científicas com as palavras-chave utilizadas nas três bases de dados previamente mencionadas, e, embora todas abordem temas correlatos, as publicações não tratam diretamente sobre o processo de elaboração de planos operacionais no setor portuário.

\section{PROCEDIMENTOS METODOLÓGICOS}

O Artigo 10 da Portaria SEP/PR n 3/2014 indica como primeira diretriz para a elaboração do PDZ, o "atendimento às políticas e diretrizes nacionais para o setor portuário em consonância com as demais políticas e diretrizes nacionais e regionais de desenvolvimento social, econômico e ambiental" (BRASIL, 2014). Assim, as ações operacionais a serem elaboradas devem estar alinhadas às políticas, diretrizes e instrumentos de planejamento aplicáveis ao setor portuário, bem como devem ser identificados os respectivos vínculos e correlações de cada uma das ações do plano operacional com as definições de cada instrumento.

Desta forma, cabe avaliar não somente as diretrizes estratégicas setoriais do sistema portuário, mas também o alinhamento com a visão das estratégias da política nacional de transportes, assim como das diretrizes de desenvolvimento sustentável. A proposição de um método de formação de um plano operacional para autoridades portuárias é bastante complexo, e considera diversos elementos físicos e operacionais, além da interação com diversos atores que atuam nos portos, sejam órgão anuentes, fiscalizadores e reguladores, operadores, embarcadores, agentes e despachantes.

No método aqui apresentado, propõe-se a análise do alinhamento com as diretrizes estratégicas de instrumentos de planejamento setorial, respeitando a avaliação de pelo menos 10 instrumentos de planejamento.

O primeiro destes é a avaliação dos Objetivos de Desenvolvimento Sustentável (ODS), que abordam uma visão global de desenvolvimento sustentável. Propostos em 2015 pela Organização das Nações Unidas (ONU) a seus países-membros, os ODS são 17 objetivos e 169 metas concebidas em conjunto entre países, empresas, instituições e sociedade civil (PNUD; IPEA; FJP, 2013). Os ODS representam uma nova agenda de desenvolvimento sustentável para os próximos 15 anos, conhecida como a Agenda 2030 (PACTO GLOBAL, [20--]).

Outro aspecto considerado é o alinhamento com a Política Nacional dos Transportes (PNT), desenvolvida pelo Ministério da Infraestrutura e que busca elencar todos os modos de transporte e não somente o sistema portuário, trazendo assim uma visão integrada dos modais. A PNT é o documento orientador do setor de transportes brasileiro, que define princípios, objetivos, diretrizes fundamentais $e$ instrumentos para $o$ planejamento e sua 
implementação, e foi publicada em 2018 pelo então Ministério dos Transportes, Portos e Aviação Civil (MTPA). No documento, são definidos oito princípios e 21 estratégias governamentais (linhas de ação), os quais norteiam a elaboração e a execução das políticas, dos planos, dos programas e dos projetos do setor de transportes brasileiro. A PNT tem como missão "induzir o desenvolvimento econômico e socioambiental, com a promoção da infraestrutura logística de transporte e, dessa forma, propiciar o aumento da competitividade e a redução das desigualdades presentes no país" (BRASIL, 2018a).

Também deve-se avaliar as Diretrizes Socioambientais dos Transportes, instituídas pelo MTPA em 2016 com uma visão focada nos aspectos socioambientais direcionadas aos sistemas de transportes nacional. Tais diretrizes visam trazer melhorias para a atuação setorial, representando uma base para inserção da variável socioambiental nos empreendimentos de transportes, em todas as suas fases de planejamento, projeto, execução ou operação. Assim, as diretrizes são embasadas em quatro princípios gerais: "Da viabilidade e valoração socioambiental dos sistemas de transportes; Do respeito às necessidades sociais e à conservação do meio ambiente; Do desenvolvimento sustentável; e Dos sistemas de transporte de baixo carbono e resilientes à mudança do clima" (BRASIL, [2016], p. 15).

Tem-se o Plano Nacional de Logística Portuária (PNLP), que é o planejamento maior em termos de visão estratégica para o setor portuário brasileiro, que visa identificar as vocações dos portos organizados, conforme 0 conjunto de suas respectivas áreas de influência, garantindo a eficiente alocação de recursos a partir da priorização de investimentos, evitando a superposição de esforços (BRASIL, 2014). O PNLP estabelece 18 objetivos estratégicos e 57 ações estratégicas para o setor portuário (BRASIL, 2015).

Outro instrumento a ser considerado é o Plano Mestre (PM) do complexo portuário, documento este de cunho estratégico e tático, que já traz elementos específicos para a realidade de cada porto nacional. Trata-se do instrumento de planejamento voltado à unidade portuária, que visa direcionar as ações, melhorias e investimentos de curto, médio e longo prazo no porto e em seus acessos. Ao Plano Mestre compete, dentre outras, a realização da análise estratégica do Porto (matriz SWOT), buscando a inserção do porto de forma harmoniosa no sistema portuário nacional com base nas suas vantagens competitivas. Dada a característica unitária, o número de ações estratégicas de cada Plano Mestre é variável conforme a complexidade de cada realidade portuária. Ademais, a Portaria SEP/PR n $3 / 2014$ é imperativa quando afirma que "o Plano Operacional deverá detalhar o Plano de Melhorias e Investimentos definido no Plano Mestre" (BRASIL, 2014).

O Plano Geral de Outorgas (PGO) também é relevante para a elaboração de plano operacional portuário, pois, em caráter orientativo, indica as áreas para investimentos em outorgas de novos terminais, sejam arrendamentos ou terminais de uso privado (TUP), alinhadas às diretrizes estratégicas do setor.

Ainda, o Planejamento Estratégico da Autoridade Portuária deverá ser considerado na análise, em que pode ser apresentado através de ferramentas de gestão das autoridades portuárias, direcionadas a sua realidade específica e formas de atuação. A elaboração do Plano Operacional do PDZ deve então levar em consideração o planejamento estratégico realizado pela própria Autoridade Portuária, sua identidade organizacional, bem como seus objetivos, seus indicadores e suas metas já estabelecidos. 
Há portos brasileiros que possuem também Plano de Negócio Portuário, instrumentos estes que apresentam a visão estratégica sobre a ótica comercial dos portos, e suas ações e planos operacionais para crescimento de movimentação.

Outro instrumento relevante para a análise são os Planos Diretores Municipais, que são estabelecidos por lei específica para cada município. Estes planos determinam a política de desenvolvimento urbano, compatibilizando as diretrizes da política com o uso e a ocupação do solo, de modo que impactam diretamente nos aspectos do zoneamento e expansão portuária.

Por fim, mas não menos importante, tem-se o Plano de Desenvolvimento e Zoneamento Portuário já desenvolvido para o porto analisado, em que se recomenda a avaliação da possibilidade da continuidade e aprimoramento dos planos já desenvolvidos sobre a ótica operacional.

As ações devem, portanto, ser relacionadas com os instrumentos exposto, alinhados a suas políticas e diretrizes de planejamento aplicáveis ao setor, de modo a explicitar a validação e a pertinência da execução das ações operacionais que permitiram o atingimento da visão estratégica.

A forma proposta por este método para a realização desta vinculação é através da criação de identificadores para os itens de cada um destes instrumentos, os quais são sintetizados na Figura 4.

Figura 4 - Instrumentos de verificação do Plano Operacional do PDZ

\begin{tabular}{|c|c|}
\hline Objetivos do Desenvolvimento Sustentável (ODS) & 17 Objetivos \\
\hline Política Nacional dos Transportes (PNT) & 22 Estratégias \\
\hline Diretrizes Socioambientais (DS) & 10 Temáticas de Diretrizes \\
\hline Plano Nacional de Logística Portuária (PNLP) & 18 Objetivos e 57 Ações Estratégicas \\
\hline Plano Mestre (PM) & Variável \\
\hline Planejamento Estratégico da Autoridade Portuária (PE) & Variável \\
\hline Plano Geral de Outorgas (PGO) & Variável \\
\hline Plano de Negócio Portuário (PN) & Variável \\
\hline Plano Diretor Municipal (PDM) & Variável \\
\hline Plano de Desenvolvimento e Zoneamento existente (PDZ) & Variável \\
\hline
\end{tabular}

Fonte: Elaborada pelos autores.

Partindo da analogia com a técnica $5 \mathrm{~W} 2 \mathrm{H}$, as ações do plano operacional do PDZ podem ser estruturadas em: contexto, etapas/recomendações, prazos e responsáveis.

No contexto devem ser abordados os aspectos "what" e "why", deixando claras as circunstâncias e justificativas para o estabelecimento da ação. A análise dos instrumentos de planejamento supracitados visa identificar as orientações e diretrizes previstas por cada documento, que se aplicam à 
realidade da instalação portuária em questão, caracterizando as circunstâncias e justificativas para o estabelecimento de uma ação operacional, e elencando as etapas necessárias para atendimento dessas linhas estratégicas. Desta análise diagnóstica é estabelecido o contexto de cada ação a ser inserida no plano operacional, determinando-se o componente "what", ou seja, a definição expressa do quê a ação se propõe a solucionar, e o componente "why", que justifica a necessidade de implementação de tal ação. O "how" surge então nas etapas, onde é detalhada a forma de implementação da ação, bem como recomendações fundamentais para a sua execução.

De maneira lógica, o componente "when" apresenta-se nos prazos estabelecidos para a execução de cada ação. Ressalte-se que a Portaria SEP/PR $n^{\circ}$ 3/2014 estabelece para o PDZ os horizontes de curto (4 anos), médio (10 anos) e longo (20 anos) prazos (BRASIL, 2014).

A seção de responsáveis por cada ação indica explicitamente o "who", no entanto, pode-se considerar que, ao se identificar um departamento da Autoridade Portuária responsável pela execução da ação, também é definida implicitamente o componente "where".

Em termos de custos - "how much", cabe ressaltar que os orçamentos das Autoridades Portuárias dos portos organizados brasileiros, que são as organizações responsáveis pela elaboração dos PDZs, têm como diretrizes o Plano Plurianual (PPA), a Lei de Diretrizes Orçamentárias (LDO) e a Lei Orçamentária Anual (LOA). Sendo assim, o processo de elaboração do orçamento deve cumprir etapas específicas e a sua divulgação é realizada em um relatório de gestão próprio, de modo que a inclusão de informações acerca do custo de cada ação que compõe o plano operacional é um tema sensível.

Assim, para cada ação operacional sugere-se a elaboração de uma ficha, indicando os aspectos supracitados, conforme o modelo a Figura 5:

Figura 5 - Modelo de ficha de ação do plano operacional do PDZ

\begin{tabular}{|c|c|c|c|c|c|c|c|c|c|c|c|}
\hline \multicolumn{12}{|c|}{ Contexto } \\
\hline \multicolumn{12}{|c|}{$\begin{array}{l}\text { Caracterização do contexto da elaboração da ação, abordando justificativa, objetivo e potenciais } \\
\text { impactos em caso de não implementação da ação. }\end{array}$} \\
\hline \multicolumn{4}{|c|}{ Etapa } & \multicolumn{2}{|c|}{ Prazo } & \multicolumn{6}{|c|}{ Responsáveis } \\
\hline \multicolumn{4}{|c|}{ Etapa 1} & \multirow{3}{*}{\multicolumn{2}{|c|}{$\begin{array}{l}\text { Curto / Médio / } \\
\text { Longo }\end{array}$}} & \multirow{3}{*}{\multicolumn{6}{|c|}{ Diretoria / Gerência responsável pela ação }} \\
\hline \multirow{2}{*}{\multicolumn{4}{|c|}{$\begin{array}{l}\text { Etapa } 2 \\
\text { Etapa } 3\end{array}$}} & & & & & & & & \\
\hline & & & & & & & & & & & \\
\hline \multicolumn{12}{|c|}{ Alinhamento com diretrizes do setor portuário } \\
\hline \multirow{2}{*}{$\begin{array}{c}\text { Diretriz } \\
\text { do setor } \\
\text { portuário }\end{array}$} & \multirow[b]{2}{*}{ ODS } & \multirow[b]{2}{*}{ PNT } & \multirow[b]{2}{*}{ DS } & \multicolumn{2}{|c|}{ PNLP } & \multirow[b]{2}{*}{ PM } & \multirow[b]{2}{*}{ PE } & \multirow[b]{2}{*}{ PGO } & \multirow[b]{2}{*}{ PN } & \multirow[b]{2}{*}{ PDM } & \multirow[b]{2}{*}{ PDZ } \\
\hline & & & & Objetivos & Ações & & & & & & \\
\hline Vínculos & $\mathrm{x}$ & $\mathrm{x}$ & $\mathrm{x}$ & $\mathrm{x}$ & $\mathrm{x}$ & $\mathrm{x}$ & $\mathrm{x}$ & $\mathrm{x}$ & $\mathrm{x}$ & $\mathrm{x}$ & $\mathrm{x}$ \\
\hline
\end{tabular}

Fonte: Elaborada pelos autores.

Na Figura 6, é esquematizado o processo de elaboração do plano operacional proposto pelo método, de forma resumida. 
Figura 6 - Processo proposto para a elaboração do plano operacional do PDZ

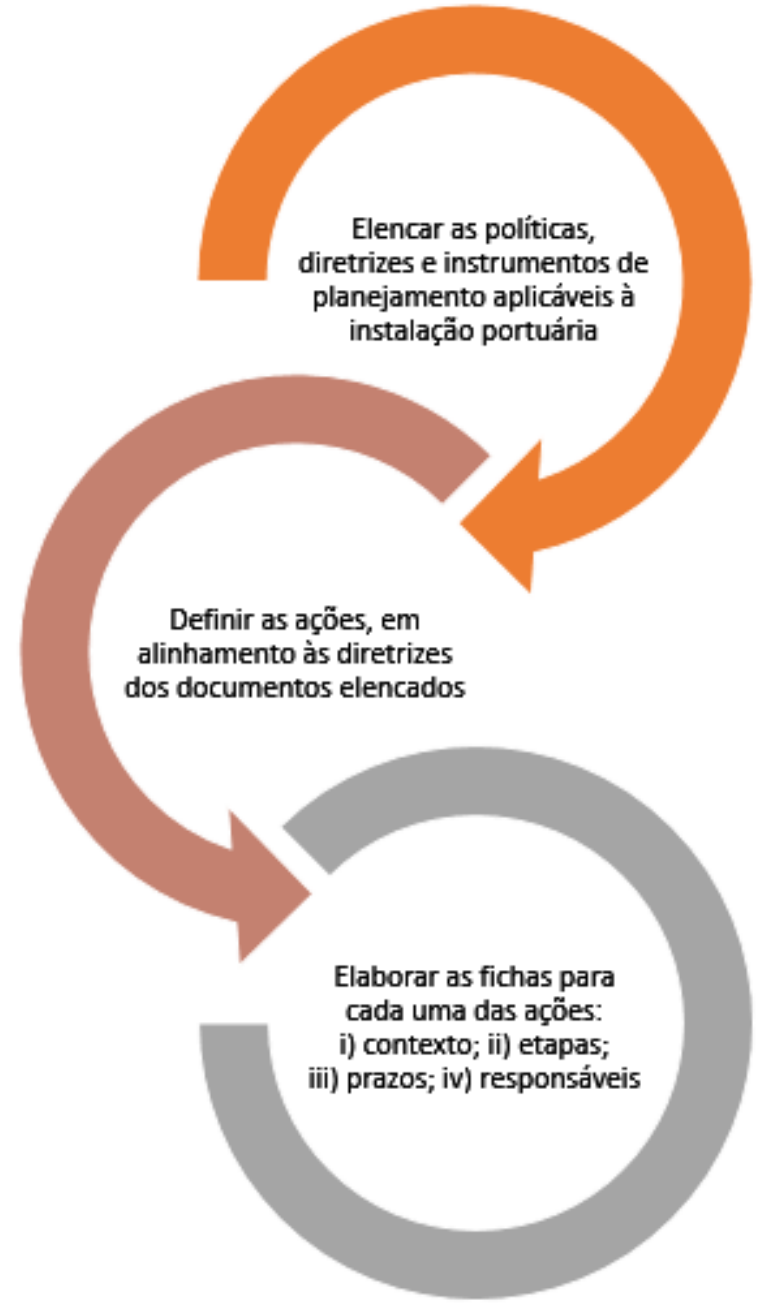

Fonte: Elaborada pelos autores.

Para que as metas definidas no plano operacional sejam alcançadas e, consequentemente, sejam atingidos os objetivos definidos nos instrumentos de planejamento estratégico do porto, é necessário um monitoramento sistemático da execução das ações, e a atuação corretiva em casos de necessidade. Sendo assim, a Figura 7 apresenta uma proposta da utilização do ciclo PDCA, com ênfase na etapa de planejamento, como um instrumento a ser incorporado ao planejamento da Autoridade Portuária, com vistas à garantia da qualidade da execução do plano operacional. 
Figura 7 - Ciclo PDCA para o plano operacional no âmbito do setor portuário

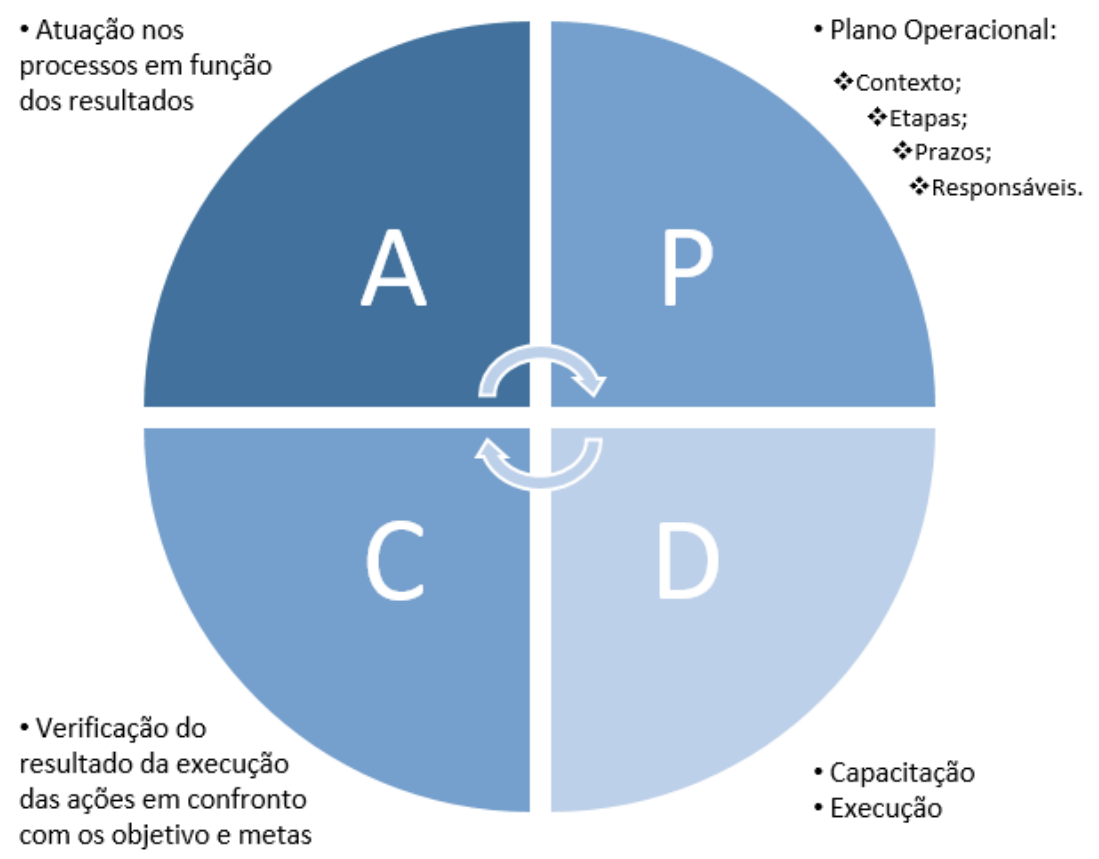

Fonte: Elaborada pelos autores.

Conforme indicado no Capítulo 2, a gestão da qualidade deve estar presente em todas as instâncias de planejamento da organização. Sendo assim, a aplicação do PDCA não deve ser tratada especificamente no âmbito do planejamento operacional, mas como uma diretriz estratégica a ser aplicada em todo tipo de planejamento realizado.

\section{RESULTADOS VALIDAÇÃO DO MÉTODO}

De forma a validar a aplicabilidade do método proposto, a sua utilização na elaboração do PDZ Porto do Itaqui é retratada neste capítulo. Não é objeto deste estudo de caso a apresentação dos resultados do PDZ de forma direta, e a validação do método é realizada sob a ótica da experiência vivenciada pela EMAP.

Nas subseções a seguir, portanto, é realizada uma contextualização acerca do Porto do Itaqui, seguida pela exposição da experiência da Autoridade Portuária com a aplicação do método proposto para a elaboração do plano operacional.

\subsection{Contextualização do Porto do Itaqui}

Historicamente, o Porto do Itaqui tem possibilitado a integração dos diversos setores da economia regional, integrando-se também aos modais de transporte e malha viária. Sendo assim, as atividades do porto têm influência direta no planejamento do uso e ocupação do solo em sua área de influência direta e indireta, que é identificada na Figura 8. 
Figura 8 - Hinterlândia do Porto do Itaqui.

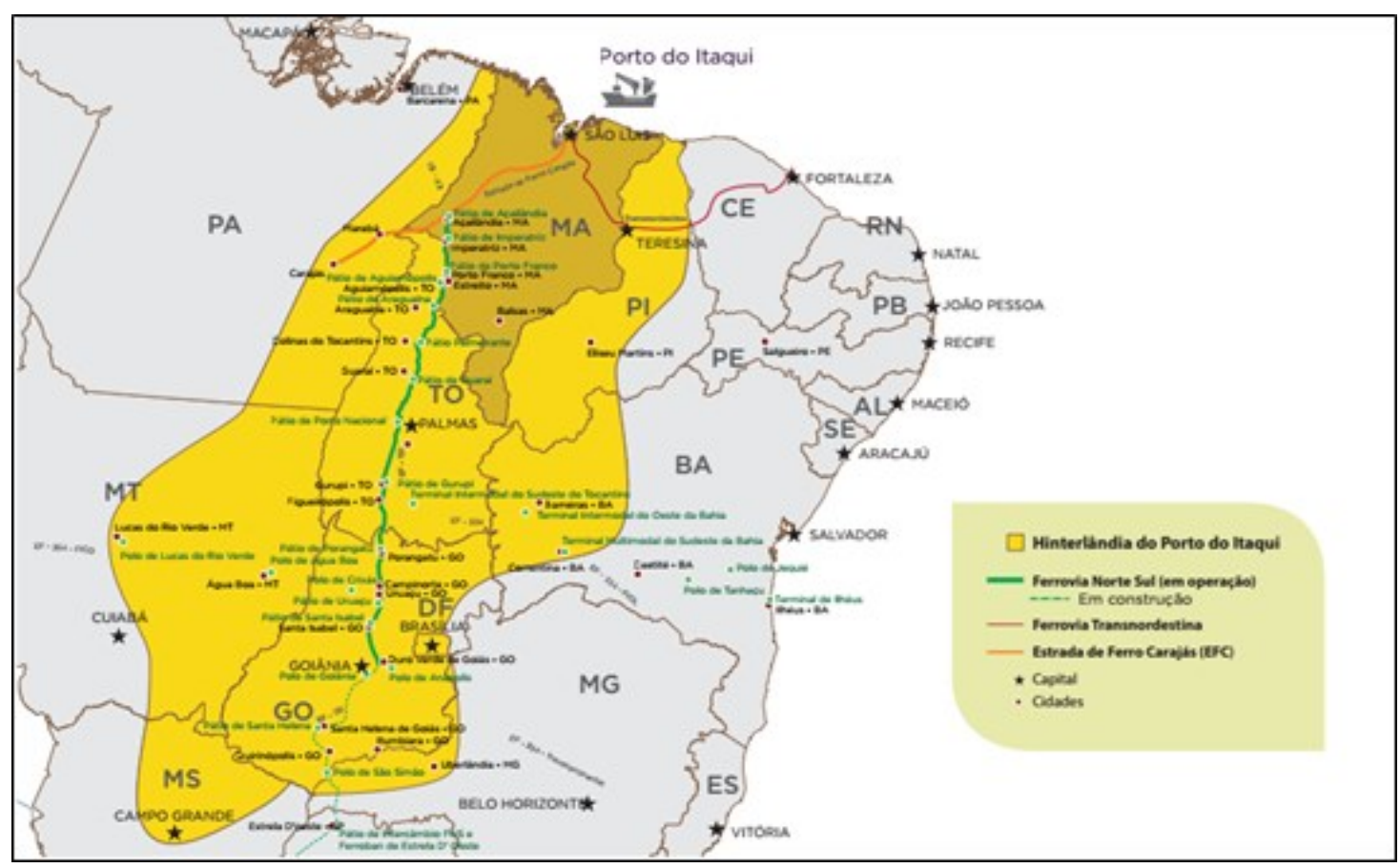

Fonte: EMAP (2019b).

Atualmente, o porto público localizado no município de São Luís (MA), faz parte do maior complexo portuário do Brasil em volume de carga movimentado e, de acordo com a ANTAQ (2019), ocupa o terceiro lugar no ranking dos portos públicos, tanto na movimentação de granel líquido (combustíveis e químicos) quanto na movimentação de granéis sólidos vegetais (soja, milho e farelo de soja), conforme exposto na Figura 9.

Figura 9 - Movimentação de granel líquido e granéis sólidos vegetais em 2018.

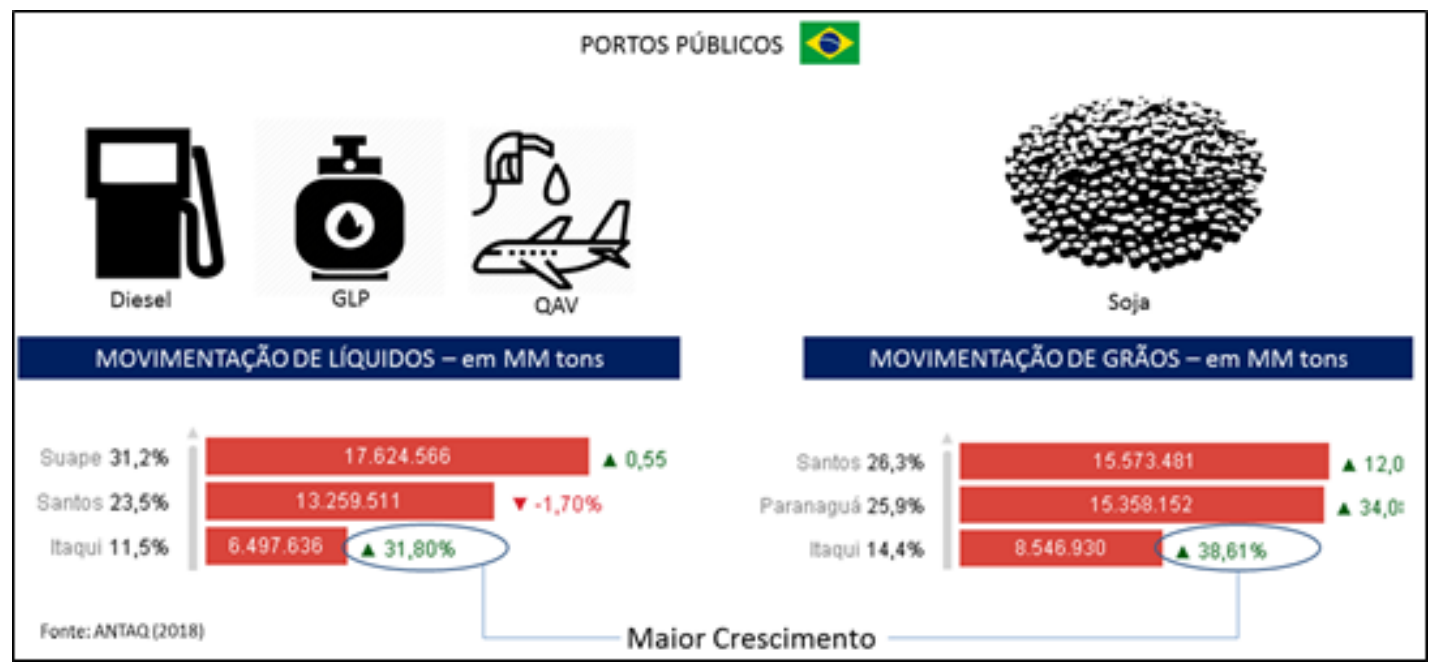

Fonte: Adaptada de ANTAQ (2019)

Segundo dados informados também pela ANTAQ (2019), o Porto do Itaqui se destaca ainda entre os portos do arco norte (portos acima do paralelo 16), como o líder em exportação de grãos, com $32 \%$ do market share deste 
segmento, e, consequentemente, também líder na importação dos fertilizantes utilizados para o preparo da terra para o grão. Os valores movimentados em 2018 nos portos concorrente e no Itaqui estão apresentados na Figura 10.

Figura 10 - Movimentação dos portos do Arco Norte em 2018

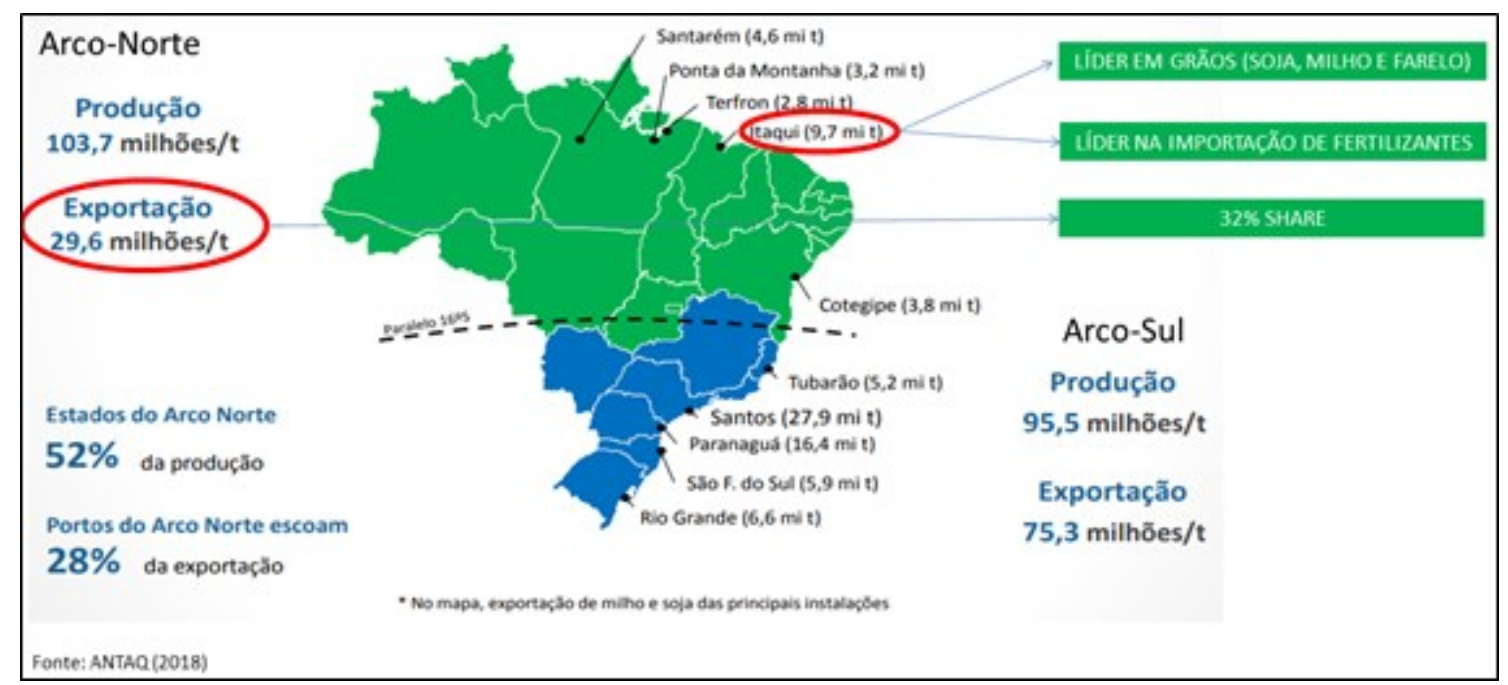

Fonte: Adaptada de ANTAQ (2019)

O Porto do Itaqui conta com uma infraestrutura de acostagem de oito berços, sendo três deles dedicados à movimentação de granéis líquidos e cinco multipropósitos, quatro sistemas mecanizados de operações de cais, capacidade estática de tancagem de $329.884 \mathrm{~m}^{3}$. A capacidade dinâmica de movimentação de grãos é de 10 milhões de toneladas por ano, considerando os volumes movimentados pelo TEGRAM e pela VLI na área do Porto Organizado. Também conta com capacidade dinâmica de 900 mil toneladas de concentrado de cobre por ano, além de pátios e armazéns que são utilizados para movimentar as demais cargas como: celulose, fertilizante, manganês, trilho, dormente, clínquer, carga de projeto, contêiner, entre outras.

Para atender às demandas existentes e futuras, o Itaqui vem ampliando sua infraestrutura através de parcerias que trouxeram ao porto projetos que estão em fase de execução, como é o caso do novo Terminal de Celulose em conjunto com um berço, ampliação de um Terminal de Fertilizantes, ampliação de tancagem e dutovias, um novo transportador e carregador de navios para exportação de grãos, que juntos somam aproximadamente $\mathrm{R} \$ 700$ milhões em investimentos.

Adicionalmente, a ANTAQ abriu dia $1^{\circ}$ de julho do ano de 2019 consulta e audiência pública para o aprimoramento das minutas jurídicas e técnicas, necessários à realização da licitação dos arrendamentos de quatro terminais portuários no Porto do Itaqui. A previsão de investimentos é de R $\$ 540$ milhões. Os terminais portuários, denominados IQI 3, IQI 11, IQI 12 e IQI 13, identificados na Figura 11, serão destinados à movimentação e armazenagem de granéis líquidos combustíveis. As áreas IQI 3 e IQI 11, são chamadas de brownfield, pois já possuem instalações industriais. A licitação desses terminais possibilitará a expansão e ampliação do armazenamento (tancagem) para $46.406 \mathrm{~m}^{3}$ e 64.897 $\mathrm{m}^{3}$, respectivamente. Já as áreas IQI 12 e IQI 13 são greenfield (sem instalações 
industriais). Com os arrendamentos, elas terão tancagem prevista de $78.724 \mathrm{~m}^{3}$ em cada.

Figura 11 - Localização das áreas para os terminais em licitação.

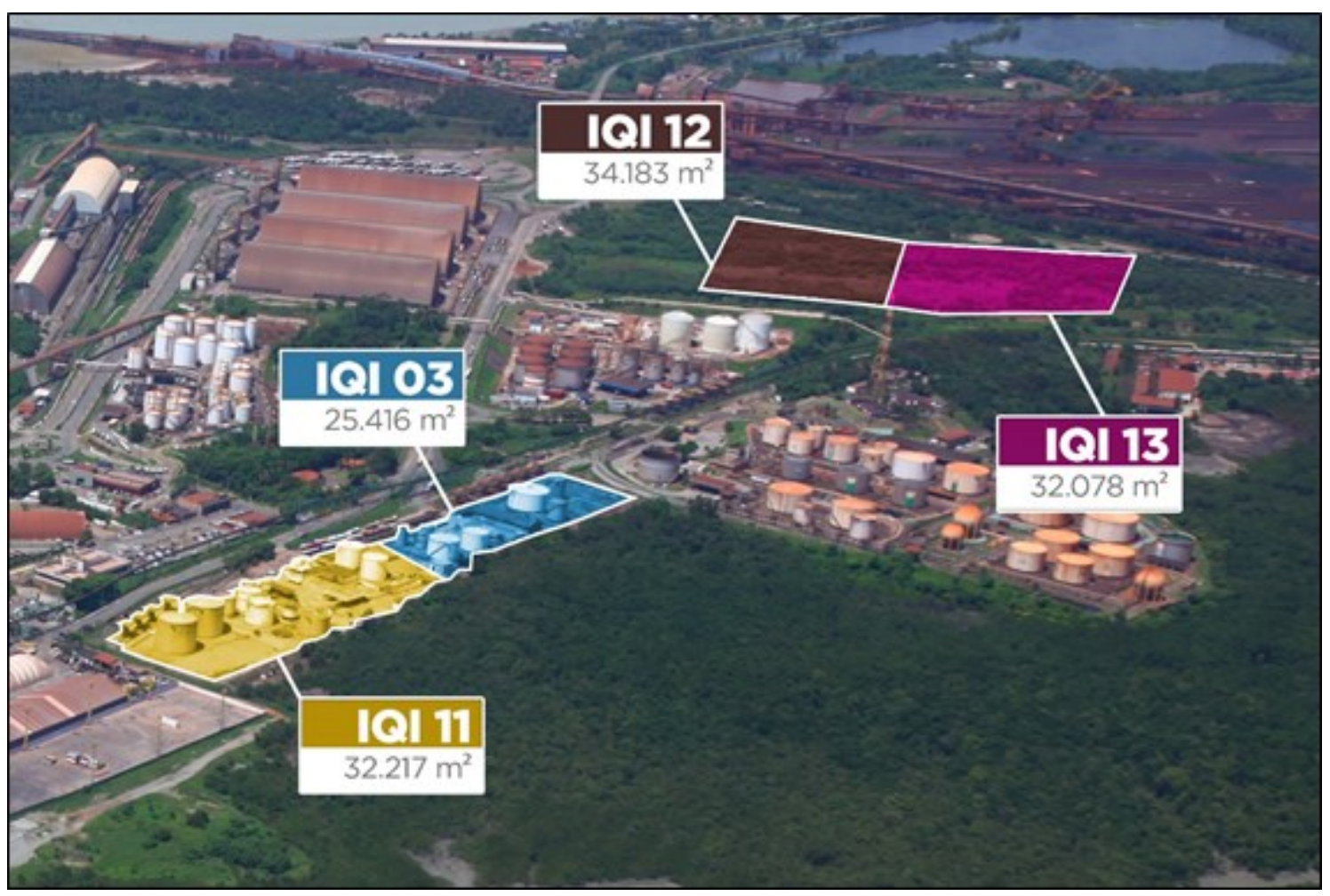

Fonte: EMAP (2019b).

Em termos de previsão de crescimento, a EMAP possui projetos bastante robustos de investimentos em novas áreas, além da promoção a melhoria operacional de outros locais já existentes no porto. Por ser um porto com tais características, de tamanha importância no contexto nacional, a formação de seu plano operacional exposto no PDZ passa a ser de complexidade elevada, por esse motivo a aplicação de métodos claros e adaptados a realidade portuária passa a ser uma premissa básica do sucesso do plano. O método ora aqui proposto foi aplicado a realidade da empresa, e no item 4.2 são apresentados os principais resultados dessa aplicação.

\subsection{Aplicação do método à realidade da EMAP}

Em virtude da importância do Porto do Itaqui no âmbito nacional e devido aos grandes desafios enfrentados por ele para se adequar às demandas atuais e futuras, a equipe de planejamento do porto avaliou a complexidade para a elaboração do novo PDZ nos moldes da Portaria SEP/PR $n^{\circ} 3 / 2014$, da Secretaria Especial de Portos, de 7 de janeiro de 2014. Levando em consideração que o documento em questão é um conjunto de estratégias ou políticas econômicas, sociais, físico-territoriais e administrativas que colaboram para o desenvolvimento político, econômico e social de sua hinterlândia, acabou então por contratar uma empresa especializada e com know-how na elaboração de PDZs. 
Esta decisão foi tomada pelos gestores e equipe técnica da EMAP, com o intuito de garantir que o novo PDZ contribuísse de forma ativa e direta para que o Porto do Itaqui atingisse seus objetivos de consolidar-se como o principal porto do Corredor Centro-Norte do país, garantindo excelência logística, competitividade, sustentabilidade e inovação, gerando valor para o Maranhão e toda a sociedade, além de ser considerada, até 2022, a empresa referência em gestão portuária no Brasil. Esse foi o alinhamento com a visão e missão do Plano Estratégico da empresa.

Visando criar um PDZ dinâmico que funcionasse como uma ferramenta de compatibilização entre as políticas de desenvolvimento urbano em nível local, regional, nacional e internacional foram estabelecidas ações e metas para a expansão racional e a otimização do uso de áreas e instalações do Itaqui. Através de uma equipe multidisciplinar que interagia intensa e diretamente com o corpo técnico da EMAP, foram realizadas extensas pesquisas bibliográficas e coletas informações in loco e nas comunidades próximas, além de outras áreas afetadas pelo porto. Assim, a elaboração do plano operacional, no âmbito do PDZ, pode ser dividida em dois momentos distintos, sendo eles:

Diagnóstico da situação atual do porto - constituída de coleta de dados e informações em conjunto com os colaboradores do da EMAP, reuniões e visitas técnicas ao porto, além de análises bibliográficas. As áreas avaliadas foram divididas em temáticas de infraestrutura, contratos e arrendamentos, zoneamento das áreas, mão-de-obra e saúde e segurança do trabalho, meio ambiente, interação porto cidade, acessos aquaviários e terrestres, conforme rege a referida Portaria.

Elaboração do plano operacional - com base no diagnóstico foi possível elencar as diretrizes operacionais que seriam compatíveis com o alinhamento estratégico e tático da empresa, seguindo a metodologia aqui proposta. Após uma primeira percepção de ações necessárias, rodadas de discussões entre as áreas de planejamento da empresa e as demais áreas da EMAP permitiram o refinamento das ações, e definição das etapas de execução e seus prazos. As melhorias propostas foram classificadas, conforme as temáticas previstas pela Portaria SEP/PR $n^{\circ} 3 / 2014$, entre: melhorias de gestão, melhorias operacionais, proposição de investimentos portuários, proposição de investimentos em acessos, proposição de reorganização de áreas e ações ambientais. $O$ alinhamento operacional com o estratégico considerou instrumentos indicados na Figura 12.

Figura 12 - Instrumentos de alinhamento do Plano Operacional do PDZ da EMAP

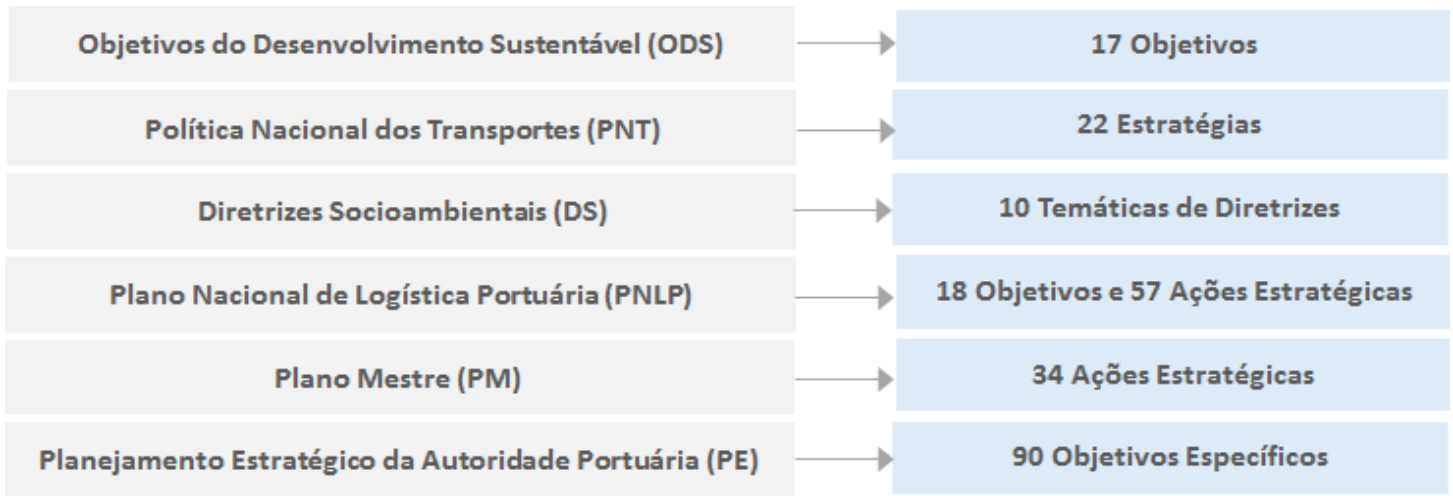

Fonte: Elaborada pelos autores. 
Cabe destacar que, no caso da EMAP, algumas etapas de alinhamento estratégico não foram consideradas de forma direta na ficha pré estabelecida de cruzamento com as ações operacionais, e sim na elaboração do diagnóstico do porto, passando a adentrar de forma indireta sobre os resultados das ações operacionais obtidas. Os documentos tratados dessa forma foram o PGO, o PDM e PDZ Anterior. O porto não dispunha de Plano de Negócios atualizado e estruturado, apesar de realizar diversas ações e atividade efetivas sobre a temática.

Da análise destes instrumentos e da aplicação do método proposto foram então elaboradas 77 ações operacionais, as quais ficaram assim distribuídas dentre as temáticas previstas pela Portaria SEP/PR n ${ }^{\circ} 3 / 2014$, conforme indica a Tabela 1.

Tabela 1 - Número de ações propostas no Plano Operacional do PDZ da EMAP

\begin{tabular}{|lc|}
\hline \multicolumn{1}{|c|}{ TEMÁTICA DO PLANO OPERACIONAL } & AÇÕES \\
\hline Melhorias de gestão & 23 \\
\hline Melhorias operacionais & 07 \\
\hline Proposição de investimentos portuários & 21 \\
\hline Proposição de investimentos em acessos & 05 \\
\hline Proposição de reorganização de áreas & 15 \\
\hline Ações ambientais & 06 \\
\hline TOTAL & 77 \\
\hline
\end{tabular}

Fonte: Elaborada pelos autores.

Após o rastreamento dos instrumentos de planejamento nas ações, foi elaborada uma análise para cada documento, com o intuito de verificar quantitativamente a contemplação do instrumento pelas ações do Plano Operacional. A Tabela 2 apresenta os instrumentos de planejamento com suas respectivas porcentagens de atendimento às ações.

Tabela 2 - Porcentagem de contemplação dos Instrumentos de Planejamento pelas ações do Plano Operacional do PDZ da EMAP

\begin{tabular}{|cc|}
\hline INSTRUMENTO DE PLANEJAMENTO & $\%$ ATENDIDO \\
\hline Objetivos de Desenvolvimento Sustentável (ODS) & $82 \%$ \\
\hline Política Nacional de Transportes (PNT) & $95 \%$ \\
\hline Diretrizes Socioambientais dos Transportes (DS) & $100 \%$ \\
\hline Plano Nacional de Logística Portuária (PNLP) - Objetivos & $100 \%$ \\
\hline Plano Nacional de Logística Portuária (PNLP) - Ações Estratégicas & $85 \%$ \\
\hline Plano Mestre do Complexo Portuário do Itaqui - 2018 & $100 \%$ \\
\hline Planejamento Estratégico EMAP - Ciclo 2019-2022 & $96 \%$ \\
\hline
\end{tabular}

Fonte: Elaborada pelos autores.

Conforme apresentado na Tabela 2, as ações definidas no Plano Operacional do PDZ do Porto do Itaqui estão 100\% alinhadas ao Plano Mestre do Complexo Portuário do Itaqui, conforme prevê a Portaria SEP/PR n 3/2014, 
VI CIDESPORT/2019

Congresso Internacional

de Desempenho Portuário

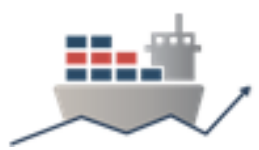

e mantém forte aderência com os instrumentos de políticas e diretrizes do setor. Os itens instrumentos que não estão vinculados ao Plano Operacional devemse ao fato de serem aplicados exclusivamente a outras instituições.

\section{CONCLUSÕES}

Conforme observado em UNCTAD (1993) e corroborado pela análise apresentada neste artigo, há uma grande incidência de portos, em âmbito internacional, que não possuem planejamento estratégico e operacional formalizados - ou que ao menos não os disponibilizam publicamente, na íntegra ou de forma sintetizada - ainda que a elaboração de tais instrumentos de planejamento seja recomendável, independentemente do porte das instalações. Além disso, observou-se, por meio da busca sistemática, que há uma carência em relação à formalização e ao estudo de métodos para a elaboração do planejamento operacional no contexto portuário, mesmo levando-se em consideração que, no caso brasileiro, é previsto na legislação do setor a elaboração de planos operacionais como parte do escopo do PDZ de cada porto.

A revisão acerca do marco legal do setor portuário nacional mostra que, embora tenha havido um longo período (entre 1986 e 2009) sem a existência de diretrizes claras para o planejamento do setor, atualmente há arcabouço consistente que orienta a elaboração do planejamento tanto por parte do Poder Concedente quanto por parte das Autoridades Portuárias dos portos organizados brasileiros. Tal situação viabiliza e estimula o desenvolvimento de métodos e ferramentas que promovam melhorias tanto na elaboração quanto na execução dos instrumentos de planejamento do setor, tendo em vista que as regras para a sua elaboração estão disponíveis e são objetivas.

Destarte, o método proposto neste artigo contribui com o aprimoramento do processo de elaboração do planejamento operacional no setor portuário, em especial para os portos brasileiros, com vistas à formalização de determinados procedimentos e ao fomento à discussão de boas práticas relacionadas ao planejamento do setor. O relato da experiência da EMAP com a implementação de tal método para a elaboração do plano operacional do PDZ do Porto do Itaqui demonstra a sua aplicabilidade e a importância de um processo robusto para a definição do plano de ações, com vistas ao atingimento dos objetivos estratégicos da Autoridade Portuária e do planejamento portuário nacional, ainda que se faça ímpar a sua avaliação ao longo do período de vigência e de execução, para a validação e melhoria contínua do método.

Ressalta-se a importância da utilização de técnicas consolidadas no mercado para a elaboração do plano operacional, como o $5 \mathrm{~W} 2 \mathrm{H}$, adaptado no método proposto para: contexto, etapas, prazos e responsáveis; e do acompanhamento de sua implementação, exemplificado neste artigo pelo PDCA. Tais práticas contribuem para o aprimoramento e profissionalização do planejamento do setor portuário, proporcionando maior controle e assertividade nas ações propostas.

Além disso, deve ser enfatizada a necessidade do alinhamento das ações propostas no nível operacional não somente às diretrizes do setor responsável pelo planejamento dos transportes em âmbito nacional, como também às diretrizes socioambientais, de modo a promover o desenvolvimento econômico e social do porto e da região com base na sustentabilidade. Este aspecto é 
VI CIDESPORT/2019

Congresso Internacional

de Desempenho Portuário

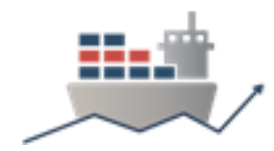

destacado tanto no método proposto quanto no relato da experiência referente à sua aplicação na elaboração do PDZ do Porto do Itaqui.

\section{REFERÊNCIAS}

ANTAQ - AGÊNCIA NACIONAL DE TRANSPORTES AQUAVIÁRIOS. Anuário estatístico. Brasília: ANTAQ, 2019. Disponível em:

http://web.antaq.gov.br/Anuario/ Acesso em: 29 ago. 2019.

BOGOSSIAN, M. P. Entraves Portuários na Movimentação de Contêineres

- Plataforma de Análise Comparativa. 2011. 302 f. Tese de Doutorado em Transportes - Departamento de Engenharia Civil e Ambiental, Universidade de Brasília, Brasília, 2011. Disponível em:

http://www.transportes.unb.br/index.php?option=com_phocadownload\&view=ca tegory\&download=2:entraves-portuarios-na-movimentacao-de-conteineresplataforma-de-analise-comparativa\&id=3:teses-de-2011\&ltemid=384. Acesso em: 8 ago. 2019.

BRASIL. Decreto $n^{\circ} 8.033$, de 27 de junho de 2013. Regulamenta o disposto na Lei $n^{\circ} 12.815$, de 5 de junho de 2013, e as demais disposições legais que regulam a exploração de portos organizados e de instalações portuárias. Diário Oficial da União, Brasília, DF, 28 jun. 2013a. Disponível em: http://www.planalto.gov.br/ccivil_03/_Ato2011-2014/2013/Decreto/D8033.htm. Acesso em: 18 de jul. 2019.

BRASIL. Lei $n^{\circ} 12.815$, de 5 de junho de 2013. Dispõe sobre a exploração direta e indireta pela União de portos e instalações portuárias e sobre as atividades desempenhadas pelos operadores portuários; altera as Leis $\mathrm{n}^{\circ}$ 5.025, de 10 de junho de 1966, 10.233, de 5 de junho de 2001, 10.683, de 28 de maio de 2003, 9.719, de 27 de novembro de 1998, e 8.213, de 24 de julho de 1991; revoga as Leis $n^{\circ} 8.630$, de 25 de fevereiro de 1993, e 11.610, de 12 de dezembro de 2007, e dispositivos das Leis $n^{\circ} 11.314$, de 3 de julho de 2006, e 11.518, de 5 de setembro de 2007; e dá outras providências. Diário Oficial da União, Brasília, DF, 5 jun. 2013b. Disponível em: http://www.planalto.gov.br/ccivil_03/_ato2011-2014/2013/lei//12815.htm. Acesso em: 18 de jul. 2019.

BRASIL. Ministério dos Transportes. Departamento Nacional de Portos e Vias Navegáveis. Master Plan for the Ports of Brazil. Methodology and Recommendations. 1974. Disponível em: http://observatorioantaq.info/index.php/2016/07/21/1974-master-plan-for-theports-of-brazil-ten-years-for-the-re-equipment-and-expansion-of-the-ports-ofbrasil-for-the-period-1975-1984/. Acesso em: 8 ago. 2019.

BRASIL. Ministério dos Transportes, Portos e Aviação Civil (MTPA). Diretrizes Socioambientais. [Brasília, DF]: MTPA, [2016]. Disponível em: http://www.transportes.gov.br/images/MEIO_AMBIENTE/MTPA_DiretrizesSocio ambientais.pdf. Acesso em: 12 ago. 2019. 
VI CIDESPORT/2019

Congresso Internacional

de Desempenho Portuário

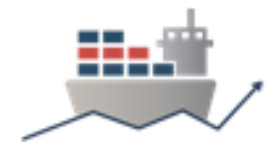

BRASIL. Ministério dos Transportes, Portos e Aviação Civil (MTPA). Política

Nacional de Transportes: Livro de Estado. Brasília, DF: MTPA, v. 1, 2018a. Ebook. Disponível em:

http://portaldaestrategia.infraestrutura.gov.br/images/PNT/livro_de_estado_vers ao_2018.pdf. Acesso em: 12 ago. 2019.

BRASIL. Ministério dos Transportes, Portos e Aviação Civil (MTPA). Secretaria Nacional de Portos. Plano Mestre: Complexo Portuário do Itaqui.

Florianópolis: LabTrans/UFSC, abr. 2018b. Disponível em:

http://infraestrutura.gov.br/planos-mestres-portos.html. Acesso em: 15 ago. 2019.

BRASIL. Secretaria de Portos da Presidência da República (SEP/PR). Portaria $\mathrm{n}^{\circ} 414$, de 30 de dezembro de 2009. Estabelece as diretrizes, os objetivos gerais e os procedimentos mínimos para a elaboração do Plano de Desenvolvimento e Zoneamento Portuário - PDZ. Diário Oficial da União, Brasília, DF, 31 dez. 2009. Disponível em:

http://pesquisa.in.gov.br/imprensa/jsp/visualiza/index.jsp?jornal=1\&pagina=2\&d ata=31/12/2009. Acesso em: 8 ago. 2019.

BRASIL. Secretaria de Portos da Presidência da República (SEP/PR). Portaria $n^{\circ} 3$, de 7 de janeiro de 2014. Estabelece as diretrizes para a elaboração e revisão dos instrumentos de planejamento do setor portuário - Plano Nacional de Logística Portuária - PNLP e respectivos Planos Mestres, Planos de Desenvolvimento e Zoneamento - PDZ e Plano Geral de Outorgas - PGO. Diário Oficial da União, Brasília, DF, 8 jan. 2014. Disponível em: http://pesquisa.in.gov.br/imprensa/jsp/visualiza/index.jsp?data=08/01/2014\&jorn al=1\&pagina=1\&totalArquivos=84. Acesso em: 12 ago. 2019.

BRASIL. Secretaria Especial de Portos da Presidência da República (SEP/PR). Plano Nacional de Logística Portuária (PNLP) 2015: Sumário Executivo. Brasília, DF, 2015. 59 p. Disponível em:

http://www.transportes.gov.br/images/SNP/planejamento_portuario/arquivos_pn Ip/SumarioExecutivoPNLP.pdf. Acesso em: 12 ago. 2019.

CHIAVENATO, Idalberto. Administração de empresas: uma abordagem contingencial. 3. ed. São Paulo: Pearson Education do Brasil, 2002. 742 p.

DAVIES, H. T. O.; CROMBIE, I. K. What is a Systematic Review? Kent, EUA: Hayward Medical Communications, 2001. Disponível em:

http://vivrolfe.com/ProfDoc/Assets/Davis\%20What\%20is\%20a\%20systematic\% 20review.pdf. Acesso em: 21 jul. 2018.

DRUCKER, Peter Ferdinand. Introdução à administração. São Paulo:

Pioneira, 1984. 713 p.

EMAP - EMPRESA MARANHENSE DE ADMINISTRAÇÃO PORTUÁRIA.

Planejamento Estratégico Ciclo 2019-2022. São Luís: EMAP, 2019a. 80 p.

Não publicado. 
VI CIDESPORT/2019

Congresso Internacional

de Desempenho Portuário

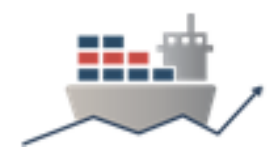

EMAP - EMPRESA MARANHENSE DE ADMINISTRAÇÃO PORTUÁRIA.

Apresentação Comercial da EMAP. São Luís: EMAP, 2019b. Não publicado.

KAPLAN, Robert S.; NORTON, David P. A estratégia em ação: balanced scorecard. 21. ed. Rio de Janeiro: Elsevier, 1997. 344 p.

MARSHALL JUNIOR, Isnard. Gestão da qualidade. Rio de Janeiro: FGV, 2003. $160 \mathrm{p}$.

MIGUEL, Paulo Augusto Cauchick. Metodologia de pesquisa em engenharia de produção e gestão de operações. 2. ed. Rio de Janeiro: Elsevier, 2012. $260 \mathrm{p}$.

PACTO GLOBAL. Os 10 princípios. São Paulo, [20--]. Disponível em: http://pactoglobal.org.br/10- principios/. Acesso em: 12 ago.

2019.

PALADINI, Edson P. Gestão estratégica da qualidade: princípios, métodos e processos. 2. ed. São Paulo: Atlas, 2009. xvii, 220 p.

PARÉ, G. KITSIOU, S. Methods for Literature Reviews. In: LAU, F.; KUZIEMSKY, C. (Eds.). Handbook of eHealth Evaluation: An Evidence-based Approach. Victoria, EUA: University of Victoria, 2017.

PETTICREW, M.; ROBERTS, H. Systematic reviews in the social sciences: a practical guide. Malden, EUA: Blackwell Publishing, 2006.

PNUD - PROGRAMA DAS NAÇÕES UNIDAS PARA O DESENVOLVIMENTO; IPEA - INSTITUTO DE PESQUISA ECONÔMICA APLICADA; FJP FUNDAÇÃO JOÃO PINHEIRO. O Índice de Desenvolvimento Humano Municipal Brasileiro. Brasília, DF: PNUD; IPEA; FJP, dez. 2013. (Série Atlas do Desenvolvimento Humano no Brasil 2013). Disponível em: http://atlasbrasil.org.br/2013/data/rawData/publicacao_atlas_municipal_pt.pdf. Acesso em: 12 ago.

2019.

PIANC - THE WORLD ASSOCIATION FOR WATERBORNE TRANSPORT INFRASTRUCTURE. Masterplans for the Development of Existing Ports. PIANC Report $n^{\circ} 158$ - Maritime Navigation Commission. Bruxelas: PIANC Secrétariat Général, 2014.

PORT HEDLAND PORT AUTHORITY. Port Development Plan 2012-2016. 2012. Disponível em: https://www.pilbaraports.com.au/PilbaraPortsAuthority/media/Documents/PORT \%20HEDLAND/Planning\%20and\%20Development/PHPA-Development-PlanBook_LowRes.pdf. Acesso em: 22 ago. 2019. 
VI CIDESPORT/2019

Congresso Internacional

de Desempenho Portuário

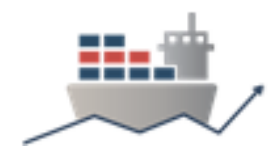

PORT METRO VANCOUVER. Land Use Plan. 2014. Disponível em:

https://www.portvancouver.com/wp-content/uploads/2015/06/port-metrovancouver-land-use-plan-english.pdf. Acesso em: 22 ago. 2019.

PORT OF BRISBANE. Brisbane Port: Land Use Plan 2015. 2015. Disponível em: https://www.portbris.com.au/getmedia/e694caaf-eb97-4b3b-83bceddc85eb655c/Brisbane-Port-Land-Use-Plan-2015.pdf. Acesso em: 22 ago. 2019.

PORT OF MELBOURNE CORPORATION. Port Development Plan 20062035. 2006. Disponível em:

https://www.parliament.vic.gov.au/images/stories/committees/pomsc/Transcript s/port-development-plan-2006-35.pdf. Acesso em: 22 ago. 2019.

PORT OF ROTTERDAM AUTHORITY. Port Vision 2030. 2011. Disponível em: https://www.portofrotterdam.com/sites/default/files/upload/Port-Vision/PortVision-2030.pdf. Acesso em: 22 ago. 2019.

PORT OF SEATTLE. Long Range Plan 2018-2022. 2018. Disponível em: https://www.portseattle.org/sites/default/files/2018-

05/POS_2017_LRP_Web_Commission_4-26-18.pdf. Acesso em: 22 ago. 2019.

SILVA, Diogo Piloni e. Proposta de Modelo de Planejamento para o Setor Portuário Nacional face à Lei 12.815/13.2013. 62 f. TCC (Especialização) Curso de Especialização em Engenharia e Gestão Portuária, Centro Tecnológico, Departamento de Engenharia Civil, Universidade Federal de Santa Catarina, Florianópolis, 2013. Disponível em:

https://www.infraestrutura.gov.br/images/arquivos_engenharia_gestao_portuari a/diogo-piloni.pdf. Acesso em: 8 ago. 2019.

THE PORT AUTHORITY OF NEW YORK AND NEW JERSEY. Port Master Plan 2050. 2019. Disponível em: https://www.panynj.gov/port/pdf/port-masterplan-2050.pdf. Acesso em: 22 ago. 2019.

THE PORT OF LOS ANGELES. Port Master Plan. 2018. Disponível em: https://kentico.portoflosangeles.org/getmedia/adf788d8-74e3-4fc3-b774c6090264f8b9/port-master-plan-update-with-no-29_9-20-2018. Acesso em: 22 ago 2019.

UNCTAD - UNITED NATIONS CONFERENCE ON TRADE AND DEVELOPMENT. Strategic Planning for Port Authorities. 1993. Disponível em: https://unctad.org/en/Docs/shipd646_en.pdf. Acesso em: 13 ago. 2019.

YIN, Robert K. Applications of case study research. Newbury Park: Sage, 1993. $130 \mathrm{p}$. 